\title{
Clinicopathological analysis of basal cell carcinoma of the anal region and its distinction from basaloid squamous cell carcinoma
}

\author{
Deepa T Patil, John R Goldblum and Steven D Billings \\ Department of Anatomic Pathology, Cleveland Clinic, Cleveland, OH, USA
}

\begin{abstract}
Basal cell carcinoma of the anal region is rare and morphologically difficult to distinguish from basaloid squamous cell carcinoma, particularly on biopsies. This distinction has therapeutic and prognostic implications. We reviewed morphological features of 9 basal cell carcinomas and 15 basaloid squamous cell carcinomas from the anal region diagnosed during 1993-2011 and determined the utility of Ber-EP4, BCL2, TP63, CK5/6, CDKN2A, and SOX2 as diagnostic tools. Immunostains were scored in a semi-quantitative manner $(1+-1-10 \%, 2+-11-50 \%, 3+->50 \%)$. All basal cell carcinomas were located in the perianal region, while all basaloid squamous cell carcinomas originated in the anal canal/anorectum. Nodular subtype of basal cell carcinoma was the most common subtype. Retraction artifact was the only significant distinguishing histological feature of basal cell carcinoma compared with basaloid squamous cell carcinoma ( $88 \%$ vs $26 \%$; $P=0.04)$. Atypical mitoses were more common in basaloid squamous cell carcinomas $(71 \%$ vs $11 \% ; P=0.05)$. An in situ component was only present in basaloid squamous cell carcinomas, and was noted in 6/15 cases. Basal cell carcinomas had 2-3 + Ber-EP4 (basal cell carcinoma $100 \%$ vs basaloid squamous cell carcinoma $40 \% ; P<0.001$ ) and BCL2 immunoreactivity (basal cell carcinomas $100 \%$ vs basaloid squamous cell carcinoma $33 \% ; P<0.001$ ). Diffuse CDKN2A and SOX2 expression was seen only in basaloid squamous cell carcinomas (basal cell carcinoma $0 \%$ vs basaloid squamous cell carcinoma $93 \% ; P<0.001$ ). There was no difference in TP63 and CK5/6 expression. Perianal location, retraction artifact, and lack of atypical mitoses are histological features that help distinguish basal cell carcinoma from basaloid squamous cell carcinoma. An in situ component, when present, supports the diagnosis of basaloid squamous cell carcinoma. Immunostains are extremely helpful as diffuse Ber-EP4 and BCL2 expression is a feature of basal cell carcinoma and basaloid squamous cell carcinoma is typified by diffuse CDKN2A and SOX2 expression.

Modern Pathology (2013) 26, 1382-1389; doi:10.1038/modpathol.2013.75; published online 19 April 2013
\end{abstract}

Keywords: Anal; basal cell carcinoma; basaloid squamous cell carcinoma; perianal; SOX2

Anal carcinomas account for nearly $2 \%$ of all colorectal malignancies. Squamous cell carcinomas are the most common type of tumors that arise within the anal canal and perianal region, the basaloid variant being the most common phenotype. By contrast, basal cell carcinomas of the anal/ perianal region are extremely rare and comprise

Correspondence: Dr DT Patil, MD, Department of Anatomic Pathology/L-25, Cleveland Clinic, 9500 Euclid Avenue, Cleveland, $\mathrm{OH} 44195$, USA.

E-mail: patild@ccf.org

Results of this study were presented, in part, at the 101st United States and Canadian Academy of Pathology Annual Meeting, Vancouver, Canada, March 2012.

Received 27 December 2012; revised 26 February 2013; accepted 27 February 2013; published online 19 April 2013
$0.2 \%$ of all anorectal neoplasms. ${ }^{1}$ Basaloid squamous cell carcinoma and basal cell carcinoma show overlapping histological features. Both tumors are composed of nests of oval cells with moderate amount of eosinophilic to basophilic cytoplasm, peripheral nuclear palisading, and variable mitotic activity. Some differences do exist; squamous cell carcinomas arise from a known precursor lesion (anal squamous intraepithelial neoplasia) while basal cell carcinomas do not have a well-defined precursor. Squamous cell carcinomas may either arise within the anal canal $(2 \mathrm{~cm}$ length of anal canal that extends from the anal verge to the dentate line) or at the anal margin/perianal skin (defined as the anatomical region between the distal end of the anal canal and $5 \mathrm{~cm}$ margin of perianal skin beyond the 
anal verge) while basal cell carcinomas usually arise at the anal margin. Rarely, basal cell carcinomas may extend from the anal margin and occur as a contiguous mass, extending into the anal canal. Thus, distinguishing these two entities can be challenging, especially on limited biopsy samples.

The role of immunohistochemical markers such as Ber-EP4 ${ }^{2-4}$ and BCL $2^{5-7}$ to differentiate cutaneous basal cell carcinomas from squamous cell carcinomas has been well documented. Similarly, CDKN2A immunohistochemistry is now routinely employed as a surrogate marker for HPV-induced anal squamous dysplasia and carcinomas. ${ }^{8,9}$ As these markers have not been systematically investigated in anal basal cell carcinomas, we decided to interrogate their utility in distinguishing these two entities.

Sex-determining region Y-box 2 or SOX2 gene encodes for a transcription factor that preserves the pluripotential function of stem cells. ${ }^{10}$ Recently, Long and Hornick ${ }^{11}$ demonstrated increased expression of SOX2 in anal squamous cell carcinomas compared with adenocarcinomas. In addition to SOX2, the pattern of expression of squamous cell differentiation markers such as TP63 and cytokeratin 5/6 has never been evaluated in basal cell carcinomas of the anal region.

Basaloid squamous cell carcinomas are aggressive tumors with a tendency to recur and metastasize to regional lymph nodes. They are often subject to chemoradiation therapy with or without surgery. By contrast, basal cell carcinomas are typically treated with wide local excision, and rarely need any subsequent therapy. Given the prognostic and therapeutic implications of this distinction, we performed a systematic retrospective analysis of a series of anal/ perianal basal cell carcinomas and basaloid squamous cell carcinomas to evaluate the morphological differences between the two entities and assessed the utility of a panel of aforementioned immunohistochemical markers to aid in this distinction.

\section{Materials and methods}

\section{Histological Review}

Following approval by Cleveland Clinic's Institutional Review Board, we performed a database search for basal cell carcinomas and basaloid squamous cell carcinomas/squamous cell carcinoma with basaloid features diagnosed between January 1993 and July 2011. Besides documenting patient age, gender, and tumor location, hematoxylin and eosin-stained slides were reviewed for the following histological features: connection with surface epithelium/epidermis, presence of keratinization, necrosis, peripheral palisading, tumor retraction artifact, cystic degeneration, inflammatory response, and mitotic activity. Basal cell carcinomas were further subtyped based on their architectural growth pattern and differentiation.

\section{Immunohistochemical Analysis}

The details of antibodies are shown in Table 1. Cytoplasmic and membranous expression of BerEP4, BCL2, CK5/6, nuclear expression of TP63, SOX2, and nuclear and/or cytoplasmic expression of CDKN2A were evaluated in a semi-quantitative manner as follows: $1+-1-10 \%$ cells, $2+-11-$ $50 \%$ cells, and $3+->50 \%$ cells. Immunoreactivity in $>10 \%$ cells was considered to be positive. In addition, the intensity of staining (weak, moderate, or strong) was also documented.

\section{Statistical Analysis}

Dichotomous measures were compared using the Fisher's exact or chi-square test test. Additionally, differences in the histological variables between the two groups were also analyzed. A $P$-value of $<0.05$ was considered statistically significant.

\section{Results}

\section{Subject Demographics}

A total of 9 patients with basal cell carcinomas and 15 patients with basaloid squamous cell carcinomas formed the cohort of this study. In both the groups, women were more commonly affected than men (female: male ratio $=4: 1$-basal cell carcinoma; 2:1-basaloid squamous cell carcinoma). Subjects diagnosed with basal cell carcinoma were slightly older than those diagnosed with basaloid squamous cell carcinoma (71 vs 62 years; $P=0.09)$. All 9 $(100 \%)$ basal cell carcinomas were located in the perianal region/anal margin. In one example, the tumor presented as contiguous mass extending from the anal margin to the anal canal. All 15 basaloid squamous cell carcinomas $(100 \%)$ arose within the anal canal. Of the nine patients with basal cell carcinoma, four had history of cutaneous basal cell carcinomas, including one with history of Gorlin syndrome. Three of nine basal cell carcinoma patients had other associated malignancies; two

Table 1 Details of antibodies evaluated in this study

\begin{tabular}{|c|c|c|c|}
\hline Antigen & Clone & Supplier & Dilution \\
\hline Ber-EP4 & Ber-EP4 & $\begin{array}{l}\text { DAKO, Carpinteria, } \\
\text { CA, USA }\end{array}$ & $1: 10$ \\
\hline BCL2 & 124 & $\begin{array}{l}\text { Cell Marque, Rocklin, } \\
\text { CA, USA }\end{array}$ & Predilute \\
\hline TP63 & $4 \mathrm{~A} 4$ & $\begin{array}{l}\text { Ventana, Tucson, AZ, } \\
\text { USA }\end{array}$ & Predilute \\
\hline Cytokeratin 5/6 & D5/16B4 & $\begin{array}{l}\text { Millipore, Billerica, } \\
\text { MA, USA }\end{array}$ & $1: 150$ \\
\hline CDKN2A & $\mathrm{E} 6 \mathrm{H} 4$ & $\begin{array}{l}\text { MTM Laboratories, } \\
\text { Heidelberg, Germany }\end{array}$ & Predilute \\
\hline SOX2 & D6D9 & $\begin{array}{l}\text { Cell Signaling, } \\
\text { Danvers, MA, USA }\end{array}$ & $1: 10$ \\
\hline
\end{tabular}


were diagnosed with infiltrating ductal carcinoma of breast and one had received treatment for diffuse large B-cell lymphoma. In the basaloid squamous cell carcinoma cohort, one subject had undergone hysterectomy for cervical squamous cell carcinoma and another had a history of infiltrating ductal carcinoma of breast.

\section{Histological Review and Analysis}

The subtypes of basal cell carcinomas included nodular (4/9), nodular/micronodular (2/9), nodular/ infiltrative (1/9), nodular/superficial (1/9), and superficial (1/9). In each example, the tumor was composed of round to oval cells with minimal cytoplasm, indistinct cell borders, and fine-to-coarse nuclear stippling. Although mitotic activity was evident, atypical mitotic figures were not present in any of the examples. The tumor nests demonstrated distinct peripheral nuclear palisading and most cases also showed a slit-like stromal retraction artifact around these nests. Basaloid squamous cell carcinomas were characterized by a solid and lobular growth pattern composed of basaloid cells with minimal cytoplasm, increased nuclear to cytoplasmic ratio, and pleomorphic, hyperchromatic nuclei, with readily visible nucleoli. Frequent mitotic activity, including atypical mitotic figures, was noted in all the cases of basaloid squamous cell carcinoma. The tumor nests showed peripheral nuclear palisading and with surrounding stromal fibroplasia. A comparative analysis of histological features is summarized in Table 2. Briefly, the majority of basal cell carcinomas (89\%) showed a distinct connection with the overlying squamous epithelium/epidermis. This feature was documented in $8 / 14(57 \%)$ cases of basaloid squamous cell carcinomas in which surface epithelium was available for evaluation. Squamous differentiation in the form of keratinization was noted in both basal cell carcinomas and basaloid squamous cell carcinomas (56\% vs 67\%). Tumor necrosis was more frequently associated with basaloid squamous cell carcinomas compared with basal cell carcinomas (60\% vs $33 \%$ ). None of these differences were found to be statistically significant. Similarly, the presence of cystic change and inflammation did not help in separating the two entities (Table 2). In contrast to these features, tumor retraction artifact was significantly associated with basal cell carcinomas as compared with basaloid squamous cell carcinomas $(89 \%$ vs $27 \% ; P=0.037$ ) (Figures 1 and 2). Both basal cell carcinomas and basaloid squamous cell carcinomas showed mitotic activity; however, atypical mitotic figures were predominantly seen in basaloid squamous cell carcinomas $(71 \%$ vs $11 \% ; P=0.05)$. Nuclear palisading towards the periphery of tumor nests was slightly more predominant in basal cell carcinomas compared with basaloid squamous cell carcinomas, and this difference approached
Table 2 Comparative analysis of histological differences between basal cell carcinoma and basaloid squamous cell carcinoma of the anal region

\begin{tabular}{|c|c|c|c|}
\hline Histological feature & $\begin{array}{l}\text { Basal cell } \\
\text { carcinoma }\end{array}$ & $\begin{array}{c}\text { Basaloid } \\
\text { squamous } \\
\text { cell carcinoma }\end{array}$ & $\mathrm{P}$-value \\
\hline $\begin{array}{l}\text { Connection with overlying } \\
\text { squamous epithelium }\end{array}$ & 8/9 (89\%) & $8 / 14(57 \%)$ & 0.178 \\
\hline Squamous differentiation & $5 / 9(56 \%)$ & 10/15 (67\%) & 0.667 \\
\hline Tumor necrosis & $3 / 9(33 \%)$ & $9 / 15(60 \%)$ & 0.371 \\
\hline $\begin{array}{l}\text { Peripheral nuclear } \\
\text { palisading }\end{array}$ & $8 / 9(89 \%)$ & $6 / 15(40 \%)$ & 0.072 \\
\hline Tumor retraction & $8 / 9(89 \%)$ & $4 / 15(27 \%)$ & 0.037 \\
\hline Atypical mitotic figures & $1 / 9(11 \%)$ & $10 / 14(71 \%)$ & 0.05 \\
\hline Cystic change & $4 / 9(44 \%)$ & $1 / 14(7 \%)$ & 0.32 \\
\hline Inflammatory response & $3 / 9(33 \%)$ & $4 / 14(29 \%)$ & 0.89 \\
\hline
\end{tabular}

Only $P$-values in bold font represent statistically significant $P$-values.

statistical significance (89\% vs $40 \% ; P=0.07)$. Of the 15 basaloid squamous cell carcinomas, an in situ component was identified in 6 cases while none of the basal cell carcinomas showed evidence of adjacent dysplasia.

\section{Immunohistochemical Analysis}

Diffuse and strong Ber-EP4 staining was noted in all the nine basal cell carcinomas $(100 \%)$ and in $40 \%$ basaloid squamous cell carcinomas $(P<0.001$; Table 3, Figures 1 and 2). Similarly, moderate-tostrong BCL2 immunoreactivity was present in all basal cell carcinomas (100\%) compared with 5/15 $(33 \%)$ basaloid squamous cell carcinomas $(P<0.001)$. By contrast, none of the basal cell carcinomas and 14/15 (93\%) basaloid squamous cell carcinomas showed $2+/ 3+$ diffuse and strong staining with CDKN2A and SOX2 $(P<0.001)$. All basal cell carcinomas showed either no staining with CDKN2A or showed a weak, patchy immunoreactivity $(<10 \%$ cells $)$ restricted to the periphery of tumor nests. TP63 and CK5/6 expression did not differentiate the two groups, as diffuse and strong staining was observed in all the basal cell carcinomas and 13/15 basaloid squamous cell carcinomas.

\section{Clinical Follow-up}

Of the nine basal cell carcinomas, clinical follow-up information was available for eight subjects. All patients were treated with local excision and negative margins. Over a mean follow-up period of 4.1 years (range: 1-14 years; median: 2.5 years), 6 of the 8 patients were alive without evidence of local recurrence/disease. Two patients died of unrelated causes. In the basaloid squamous cell carcinoma cohort, 5 of 15 patients underwent excision alone, 4 underwent abdominoperineal resection, 4 were administered chemoradiation therapy following excision, and 2 patients were 

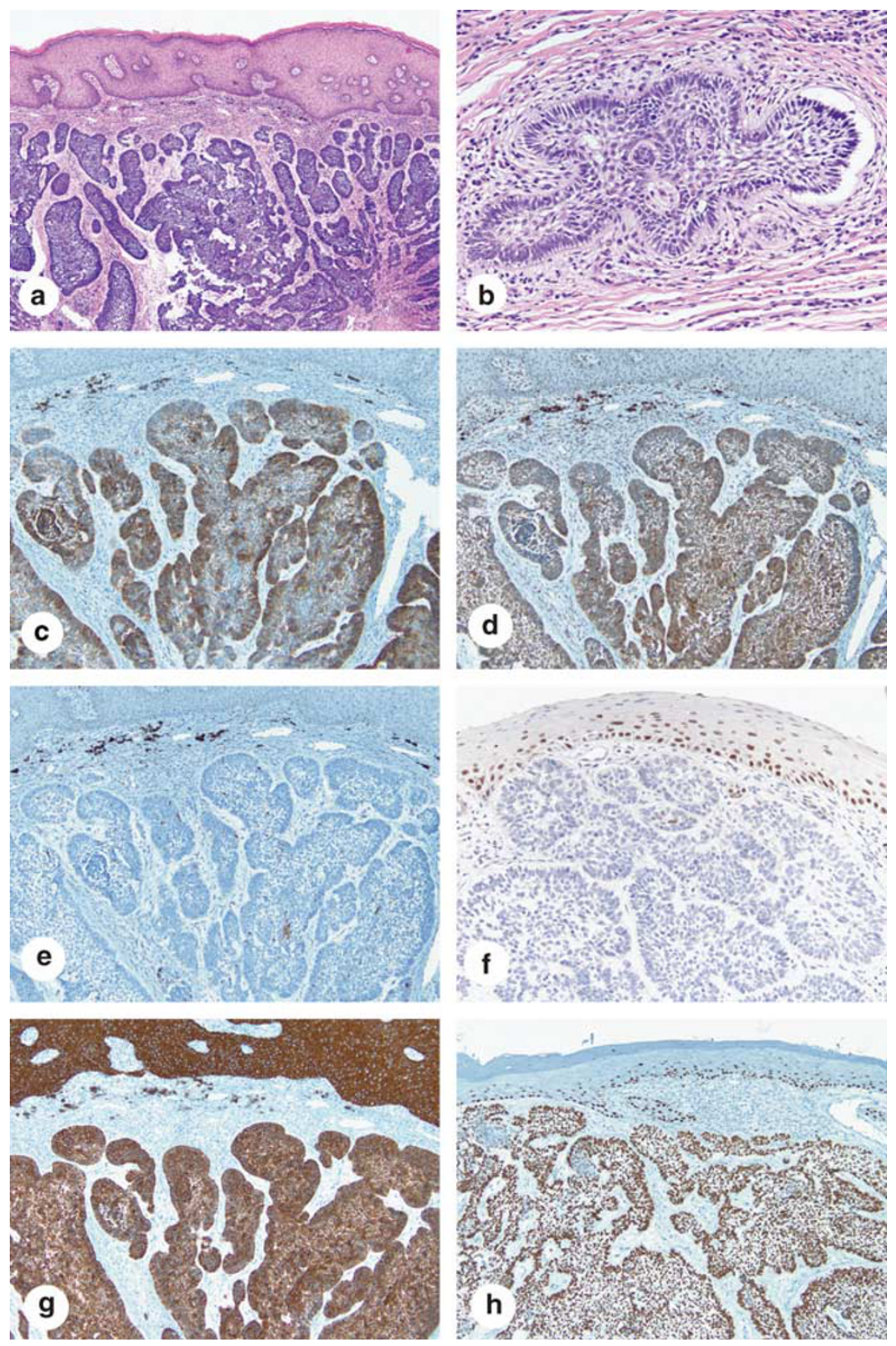

Figure $1(\mathbf{a}-\mathbf{h})$ Hematoxylin and eosin-stained section of a perianal basal cell carcinoma showing a tumor composed of basophilic nests located beneath the epidermis $(\times 20$ magnification). Higher magnification $(\times 200)$ shows the prominent peripheral nuclear palisading as well as tumor retraction artifact (clear space between the tumor cells and adjacent stroma) that is usually associated with basal cell carcinomas. Immunohistochemical markers $(\times 200$ magnification $)$ applied to this lesion show that the tumor was diffusely positive for Ber-EP4 (c), BCL2 (d), cytokeratin 5/6 (g), and TP63 (h). It did not express CDKN2A (e) or SOX2 (f).

treated with abdominoperineal resection followed by chemoradiation therapy. At the time of diagnosis, 7 of 15 patients $(47 \%)$ had lymph node and/or distant metastasis. Follow-up information was available on 12 of 15 patients with basaloid squamous cell carcinoma, with a mean follow-up period of 2.9 years (range: 1-7 years; median: 2.5 years). Of the 12 cases, 4 patients had no evidence of disease, 3 had recurrent basaloid squamous cell carcinoma, 3 died of unknown causes, and 2 died of metastatic disease.

\section{Discussion}

Basal cell carcinomas of the anal/perianal region are rare neoplasms comprising $<0.1 \%$ of all anal malignancies. Based on the 16 case reports, ${ }^{2,12-26} 4$ retrospective studies $(5,15,19$, and 34 patients) ${ }^{1,12,27,28}$ reported thus far, as well as the findings in the current study, basal cell carcinomas tend to arise as perianal ulcers or masses with central ulceration and raised edges. As in two examples in our series, they may mimic external 

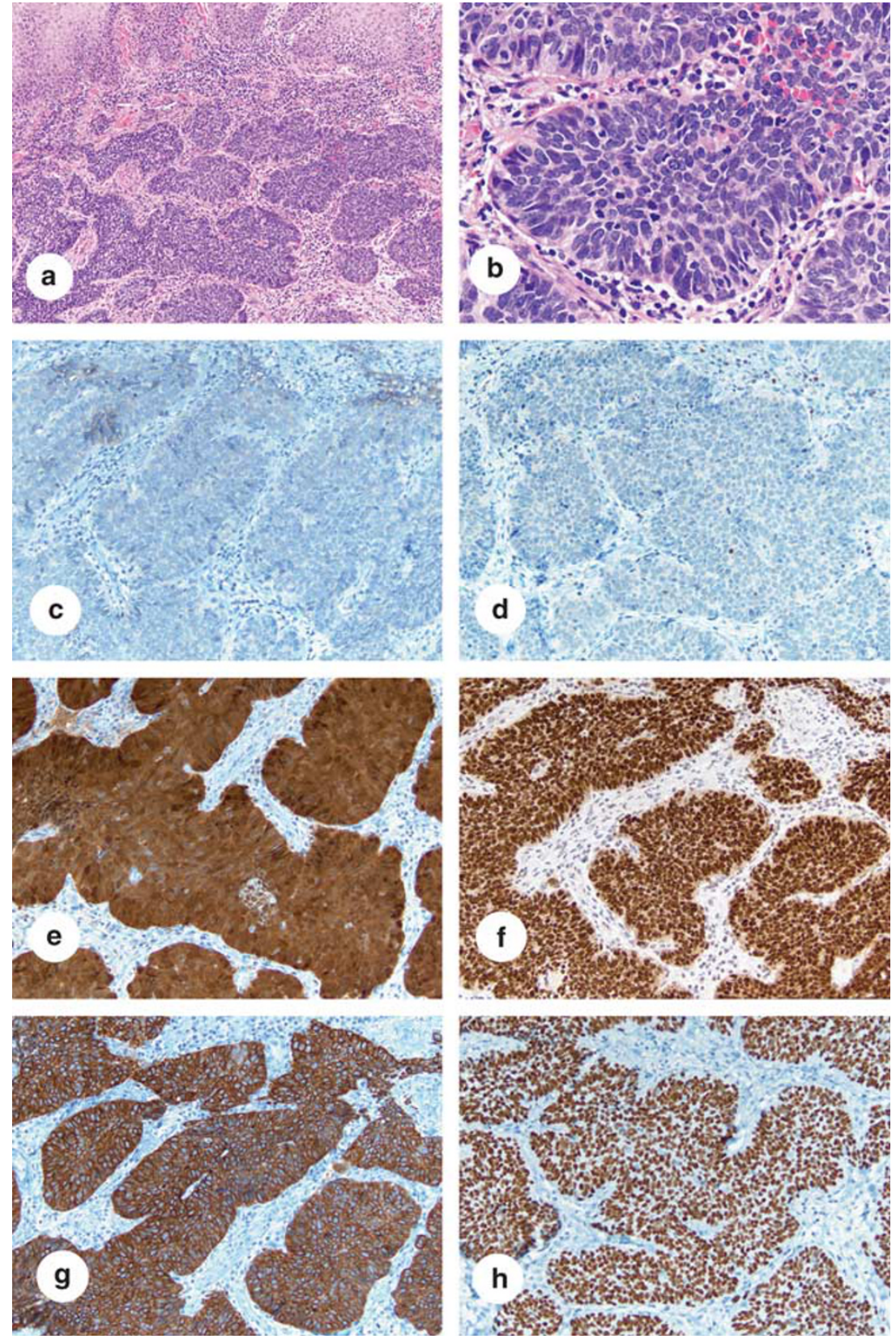

Figure 2 (a-h): Hematoxylin and eosin-stained section of an anal basaloid squamous cell carcinoma showing an infiltrating tumor composed of basophilic nests located beneath the anal squamous mucosa $(\times 20$ magnification). Higher magnification $(\times 400)$ shows some degree of peripheral nuclear palisading along with prominent cytological atypia and mitotic activity, including atypical mitotic figures. Immunohistochemical markers $(\times 200$ magnification) applied to this lesion shows that the tumor was diffusely positive for CDKN2A (e), SOX2 (f), cytokeratin 5/6 (g), and TP63 (h). It did not express Ber-EP4 (c) or BCL2 (d).

hemorrhoids or anal cysts. Similar to basal cell carcinomas elsewhere, they are characterized by tumor nests with peripheral palisading of nuclei and stromal retraction. ${ }^{29}$ Although most lesions tend to be localized and thus amenable to wide excision, they may occasionally extend into the anal canal and present as anal canal masses, as noted in one of our cases. In these clinical situations, the morphological overlap between a relatively more common neoplasm, basaloid squamous cell carcinoma, and basal cell carcinoma can pose a significant diagnostic challenge to surgical pathologists. Although case reports have alluded to the differences between these two entities, a systematic analysis of clinicopathological features has never been reported. Besides analyzing these features in 9 basal cell carcinomas and 15 basaloid squamous cell carcinomas culled over a period of 18 years, our study also evaluates the utility of immunohistochemical markers Ber-EP4, BCL2, CDKN2A, SOX2, TP63, and CK5/6 in differentiating these entities. 
Table 3 Comparative analysis of immunohistochemical markers to distinguish basal cell carcinoma from basaloid squamous cell carcinoma of the anal region

\begin{tabular}{lrrr} 
& \multicolumn{3}{c}{$\begin{array}{l}\text { Basaloid } \\
\text { squamous }\end{array}$} \\
$\begin{array}{l}\text { Immunohistochemical marker } \\
\text { (positive in }>50 \% \text { cells) }\end{array}$ & $\begin{array}{l}\text { Basal cell } \\
\text { carcinoma }\end{array}$ & \multicolumn{1}{l}{ carcinoma } & P-value \\
\hline Ber-EP4 & $9 / 9(100 \%)$ & $6 / 15(40 \%)$ & $<\mathbf{0 . 0 0 1}$ \\
BCL2 & $9 / 9(100 \%)$ & $5 / 15(33 \%)$ & $<\mathbf{0 . 0 0 1}$ \\
CDKN2A & $0 / 9(0 \%)$ & $14 / 15(93 \%)$ & $<\mathbf{0 . 0 0 1}$ \\
SOX2 & $0 / 9(0 \%)$ & $14 / 15(93 \%)$ & $<\mathbf{0 . 0 0 1}$ \\
TP63 & $9 / 9(100 \%)$ & $13 / 15(87 \%)$ & 0.36 \\
CK5/6 & $9 / 9(100 \%)$ & $12 / 15(80 \%)$ & 0.18 \\
\hline
\end{tabular}

Only $P$-values in bold font represent statistically significant $P$-values.

Similar to previous reports, ${ }^{1,2,12-28}$ all basal cell carcinomas arose in the perianal region while all basaloid squamous cell carcinomas were located within the anal canal. We found that tumor retraction artifact was the only histological feature that was significantly associated with basal cell carcinomas compared with basaloid squamous cell carcinomas. Additionally, atypical mitotic figures were more frequent in basaloid squamous cell carcinomas compared with basal cell carcinomas. Squamous dysplasia was noted in six examples and was exclusively associated with basaloid squamous cell carcinomas. In their series of five basal cell carcinomas, Gibson et $a^{27}$ noted that nodular basal cell carcinoma was the most common subtype of perianal basal cell carcinoma. This was confirmed in our study, wherein, the nodular subtype, either in its pure form or in combination with other subtypes (micronodular/infiltrative/superficial), was present in $8 / 9$ basaloid squamous cell carcinomas.

The utility of Ber-EP4 in distinguishing cutaneous squamous cell carcinomas from basal cell carcinomas has been well documented. ${ }^{2,4,13}$ Ber-EP4 antibody targets the epithelial membrane glycoproteins and most basal cell carcinomas typically demonstrate diffuse cytoplasmic and membranous expression. This holds true for perianal basal cell carcinomas and has been demonstrated in studies by Alvarez-Cañas MC et $a l^{12}$ and a recent report by Kreuter et al. ${ }^{13}$ Our study shows similar findings; all nine basal cell carcinomas exhibited diffuse membranous and cytoplasmic immunoreactivity. Interestingly, BerEP4 staining was not exclusive to the basal cell carcinoma group and $2+$ (3 cases) or $3+$ ( 3 cases $)$ staining was noted in $40 \%$ of basaloid squamous cell carcinomas. Similar to Ber-EP4, BCL2 is expressed in $67-100 \%$ of cutaneous basal cell carcinomas. $^{5,6,30}$ All anal/perianal basal cell carcinomas $(100 \%)$ in the current study also showed moderate-to-strong staining compared with only $33 \%$ of basaloid squamous cell carcinomas. It is likely that BCL2 expression in basaloid squamous cell carcinomas is a function of altered apoptotic pathway in these tumors. The only study interrogating the prognostic value of pro and antiapoptotic protein expression in anal carcinomas was by Allal et $a l .{ }^{31}$ In that study, BCL2 expression was noted in $42 \%$ of anal squamous cell carcinomas (basaloid squamous cell carcinoma comprised 64\% of their cohort) and BCL2-positive tumors were associated with a significantly better local control and disease-free survival. In their multivariate analysis, loss of BCL2 expression was found to be an independent negative factor for both local control and disease-free survival. A similar trend was observed in our study, wherein, 6 of 10 basaloid squamous cell carcinomas with lack of BCL2 expression developed recurrent disease, nodal metastasis, or distant metastasis.

Similar to studies in cutaneous squamous cell carcinomas and basal cell carcinomas, ${ }^{32-34}$ all anal/ perianal basal cell carcinomas and 13/15 basaloid squamous cell carcinomas were diffusely positive for CK5/6 and TP63 and thus did not help in distinguishing these two entities.

Human papilloma virus infection has a major role in the pathogenesis of anal squamous cell carcinoma. $^{35,36}$ In a systematic study on 29 anorectal squamous cell carcinomas, diffuse and strong CDKN2A nuclear and/or cytoplasmic staining was observed in all the cases, majority of which demonstrated a basaloid phenotype. ${ }^{8}$ Our results are comparable with this study; 14/15 (93\%) examples of basaloid squamous cell carcinomas showed diffuse and strong nuclear and cytoplasmic immunoreactivity. Thus far, only one case report has documented CDKN2A expression in perianal basal cell carcinoma. ${ }^{13}$ The authors report an HPV-negative perianal basal cell carcinoma that was diffusely positive for Ber-EP4 and showed strong nuclear and cytoplasmic CDKN2A expression. Based on studies performed in cutaneous basal cell carcinomas, ${ }^{37-39}$ it appears that a subset (up to $50 \%$ ) $^{38}$ of cutaneous basal cell carcinomas arising in sun-exposed areas can express CDKN2A; however, this is most likely a result of non-HPVrelated cell-cycle dysregulation. In our hands, none of the basal cell carcinomas expressed CDKN2A, and thus this marker was extremely helpful in separating these two entities.

The current study also illustrates the utility of SOX2 in differentiating basaloid squamous cell carcinomas from basal cell carcinomas of the anal/ perianal region. None of the basal cell carcinomas and 14/15 (93\%) basaloid squamous cell carcinomas showed nuclear SOX2 expression. These findings are in accord with the results published by Long et al, ${ }^{11}$ who documented overexpression of SOX2 in all anal squamous cell carcinomas. Additionally, all basal cell carcinomas and basaloid squamous cell carcinomas showed nuclear staining in the adjacent non-neoplastic squamous epithelium/epidermis. The staining was strongest in the basal cell layer and progressively decreased with maturing epithelium. Although SOX2 is not considered to 
be a lineage-specific marker, we found that two examples of basaloid squamous cell carcinomas that were positive for SOX2 did not react with antibodies against TP63 or CK5/6, markers that are typically expressed by most squamous cell carcinomas. During embryogenesis, SOX2 has a significant role in the development of foregut-derived organs, such as esophagus and lung. ${ }^{40}$ Our findings indicate that unlike its potential role as a cancer stem-like cell/ tumor-initiating cell marker in various cancers such as lung adenocarcinoma, ${ }^{41}$ gastric carcinoma, ${ }^{42}$ breast carcinoma, ${ }^{43}$ head and neck squamous cell carcinomas, ${ }^{44}$ and metastatic melanomas, ${ }^{45}$ it does not appear to mediate regulation of progenitor cells of the folliculo-sebaceous unit or interfollicular epidermis from which basal cell carcinomas originate. $^{29}$ The differential expression of SOX2 not only allows for a reliable distinction between basal cell carcinomas and basaloid squamous cell carcinomas but also provides opportunities for selective therapeutic intervention in basaloid squamous cell carcinomas. ${ }^{46}$

Lastly, the exact pathogenesis of basal cell carcinomas arising in non-sun-exposed areas remains unclear. In our cohort, 1/9 patients was diagnosed with Gorlin syndrome and 3/9 patients had multiple cutaneous basal cell carcinomas. It can be reasonably argued that these individuals probably have alterations in the sonic hedgehog pathway, a pathway that has been implicated in most syndromic and sporadic forms of cutaneous basal cell carcinomas. For the remainder of the cohort, it has been speculated that chronic skin trauma, scars, radiation therapy, especially for pelvic tumors, may be some of the inciting factors that trigger the molecular machinery responsible for the development of basal cell carcinomas. ${ }^{47-49}$

In summary, in this systematic comparative analysis of 9 basal cell carcinomas and 15 basaloid squamous cell carcinomas, we have shown that morphological assessment in conjunction with immunohistochemical markers can reliably distinguish basal cell carcinomas from basaloid squamous cell carcinomas of the anal/perianal region. Basal cell carcinomas usually arise in the perianal region while basaloid squamous cell carcinomas typically arise within the anal canal. Although precise localization of the tumor is helpful when approaching these tumors, on rare occasions, basal cell carcinomas may present as anal canal lesions. Compared with basaloid squamous cell carcinomas, basal cell carcinomas are significantly associated with tumor retraction artifact and lack atypical mitotic figures. The presence of an adjacent precursor lesion supports the diagnosis of basaloid squamous cell carcinoma rather than basal cell carcinoma. Immunohistochemically, diffuse BerEP4 and BCL2 staining are a feature of basal cell carcinoma while diffuse CDKN2A and SOX2 expression are almost exclusively associated with basaloid squamous cell carcinoma.

\section{Disclosure/conflict of interest}

The authors declare no conflict of interest.

\section{References}

1 Nielsen OV, Jensen SL. Basal cell carcinoma of the anusa clinical study of 34 cases. Br J Surg 1981;68:856-857.

2 Tellechea O, Reis JP, Domingues JC, et al. Monoclonal antibody Ber EP4 distinguishes basal-cell carcinoma from squamous-cell carcinoma of the skin. Am J Dermatopathol 1993;15:452-455.

3 Jones MS, Helm KF, Maloney ME. The immunohistochemical characteristics of the basosquamous cell carcinoma. Dermatol Surg 1997;23:181-184.

4 Beer TW, Shepherd P, Theaker JM. Ber EP4 and epithelial membrane antigen aid distinction of basal cell, squamous cell and basosquamous carcinomas of the skin. Histopathology 2000;37:218-223.

5 Cerroni L, Volkenandt M, Rieger E, et al. BCL2 protein expression and correlation with the interchromosomal $14 ; 18$ translocation in cutaneous lymphomas and pseudolymphomas. J Invest Dermatol 1994;102:231-235.

6 Crowson AN, Magro CM, Kadin ME, et al. Differential expression of the BCL2 oncogene in human basal cell carcinoma. Hum Pathol 1996;27:355-359.

7 Ramdial PK, Madaree A, Reddy R, et al. BCL2 protein expression in aggressive and non-aggressive basal cell carcinomas. J Cutan Pathol 2000;27:283-291.

$8 \mathrm{Lu}$ DW, El-Mofty SK, Wang HL. Expression of CDKN2A, Rb, and p53 proteins in squamous cell carcinomas of the anorectal region harboring human papillomavirus DNA. Mod Pathol 2003;16:692-699.

9 Sano T, Oyama T, Kashiwabara K, et al. Expression status of CDKN2A protein is associated with human papillomavirus oncogenic potential in cervical and genital lesions. Am J Pathol 1998;153:1741-1748.

10 Masui S, Nakatake Y, Toyooka Y, et al. Pluripotency governed by Sox 2 via regulation of Oct3/4 expression in mouse embryonic stem cells. Nat Cell Biol 2007;9:625-635.

11 Long KB, Hornick JL. SOX2 is highly expressed in squamous cell carcinomas of the gastrointestinal tract. Hum Pathol 2009;40:1768-1773.

12 Alvarez-Canas MC, Fernandez FA, Rodilla IG, et al. Perianal basal cell carcinoma: a comparative histologic, immunohistochemical, and flow cytometric study with basaloid carcinoma of the anus. Am J Dermatopathol 1996;18:371-379.

13 Kreuter A, Bechara FG, Stucker M, et al. Perianal basal cell carcinoma-unusual localization of a frequent tumor. J Dtsch Dermatol Ges 2012;10:59-61.

14 Damin DC, Rosito MA, Gus P, et al. Perianal basal cell carcinoma. J Cutan Med Surg 2002;6:26-28.

15 Kort R, Fazaa B, Bouden S, et al. Perianal basal cell carcinoma. Int J Dermatol 1995;34:427-428.

16 Rahbari H, Mehregan AH. Basal cell epitheliomas in usual and unusual sites. J Cutan Pathol 1979;6: $425-431$

17 Rosenthal D. Basal cell carcinoma of the anus: report of two cases. Dis Colon Rectum 1967;10:397-400.

18 Kraus EW. Perianal basal cell carcinoma. Arch Dermatol 1978;114:460-461.

19 Wittoesch JH, Woolner LB, Jackman RJ. Basal cell epithelioma and basaloid lesions of the anus. Surg Gynecol Obstet 1957;104:75-80. 
20 White WB, Schneiderman H, Sayre JT. Basal cell carcinoma of the anus: clinical and pathological distinction from cloacogenic carcinoma. J Clin Gastroenterol 1984;6:441-446.

21 Espana A, Redondo P, Idoate MA, et al. Perianal basal cell carcinoma. Clin Exp Dermatol 1992;17:360-362.

22 Kyzer S, Alfandari C, Bayer I, et al. Basal cell carcinoma occurring in the perianal region. Plast Reconstr Surg 1992;89:379-380.

23 Simo AC, Jarjous N, Boddaert A, et al. [Perianal basal cell carcinoma extending into the anal canal]. Gastroenterol Clin Biol 2008;32:337-338.

24 Nagendra Naidu DV, Rajakumar V. Perianal basal cell carcinoma-an unusual site of occurrence. Indian J Dermatol 2010;55:178-180.

25 Shaikh FM, Healy VC, Kavanagh EG. A common tumor, an uncommon location. Gastroenterology 2010;139:e5-e6.

26 Montagliani L, Aubert P, Vergeau B, et al. [Perianal basal cell carcinoma]. Presse Med 2004;33:389-390.

27 Gibson GE, Ahmed I. Perianal and genital basal cell carcinoma: a clinicopathologic review of 51 cases. J Am Acad Dermatol 2001;45:68-71.

28 Paterson CA, Young-Fadok TM, Dozois RR. Basal cell carcinoma of the perianal region: 20-year experience. Dis Colon Rectum 1999;42:1200-1202.

29 Crowson AN. Basal cell carcinoma: biology, morphology and clinical implications. Mod Pathol 2006; 19(Suppl 2):S127-S147.

30 Morales-Ducret CR, van de Rijn M, LeBrun DP, et al. BCL2 expression in primary malignancies of the skin. Arch Dermatol 1995;131:909-912.

31 Allal AS, Waelchli L, Brundler MA. Prognostic value of apoptosis-regulating protein expression in anal squamous cell carcinoma. Clin Cancer Res 2003;9: 6489-6496.

32 Chu PG, Weiss LM. Expression of cytokeratin 5/6 in epithelial neoplasms: an immunohistochemical study of 509 cases. Mod Pathol 2002;15:6-10.

33 Bircan S, Candir O, Kapucoglu N, et al. The expression of TP63 in basal cell carcinomas and association with histological differentiation. J Cutan Pathol 2006;33: 293-298.

34 Kaufmann O, Fietze E, Mengs J, et al. Value of TP63 and cytokeratin 5/6 as immunohistochemical markers for the differential diagnosis of poorly differentiated and undifferentiated carcinomas. Am J Clin Pathol 2001;116:823-830.

35 Duggan MA, Boras VF, Inoue M, et al. Human papillomavirus DNA determination of anal condylomata, dysplasias, and squamous carcinomas with in situ hybridization. Am J Clin Pathol 1989;92:16-21.

36 Palefsky JM, Holly EA, Gonzales J, et al. Detection of human papillomavirus DNA in anal intraepithelial neoplasia and anal cancer. Cancer Res 1991;51: 1014-1019.

37 Eshkoor SA, Ismail P, Rahman SA, et al. CDKN2A gene expression in basal cell carcinoma. Arch Med Res 2008;39:668-673.

38 Conscience I, Jovenin N, Coissard C, et al. CDKN2A is overexpressed in cutaneous carcinomas located on sun-exposed areas. Eur J Dermatol 2006;16:518-522.

39 Svensson S, Nilsson K, Ringberg A, et al. Invade or proliferate? Two contrasting events in malignant behavior governed by CDKN2A(INK4a) and an intact $\mathrm{Rb}$ pathway illustrated by a model system of basal cell carcinoma. Cancer Res 2003;63:1737-1742.

40 Ishii Y, Rex M, Scotting PJ, et al. Region-specific expression of chicken Sox2 in the developing gut and lung epithelium: regulation by epithelial-mesenchymal interactions. Dev Dyn 1998;213:464-475.

41 Sholl LM, Barletta JA, Yeap BY, et al. Sox2 protein expression is an independent poor prognostic indicator in stage I lung adenocarcinoma. Am J Surg Pathol 2010;34:1193-1198.

42 Matsuoka J, Yashiro M, Sakurai K, et al. Role of the stemness factors sox2, oct3/4, and nanog in gastric carcinoma. J Surg Res 2012;174:130-135.

43 Rodriguez-Pinilla SM, Sarrio D, Moreno-Bueno G, et al. Sox2: a possible driver of the basal-like phenotype in sporadic breast cancer. Mod Pathol 2007;20:474-481.

44 Wang X, Liang Y, Chen Q, et al. Prognostic significance of SOX2 expression in nasopharyngeal carcinoma. Cancer Invest 2012;30:79-85.

45 Chen PL, Chen WS, Li J, et al. Diagnostic utility of neural stem and progenitor cell markers nestin and SOX2 in distinguishing nodal melanocytic nevi from metastatic melanomas. Mod Pathol 2012;26:44-53.

$46 \mathrm{Hu}$ X, Ghisolfi L, Keates AC, et al. Induction of cancer cell stemness by chemotherapy. Cell Cycle 2012;11:2691-2698.

47 Ward J. Five cases of basal-cell carcinoma of the vulva. J Obstet Gynaecol Br Emp 1956;63:697-705.

48 Noodleman FR, Pollack SV. Trauma as a possible etiologic factor in basal cell carcinoma. J Dermatol Surg Oncol 1986;12:841-846.

49 Strickland PT, Creasia D, Kripke ML. Enhancement of two-stage skin carcinogenesis by exposure of distant skin to UV radiation. J Natl Cancer Inst 1985;74:1129-1134. 